\title{
CuO-Loaded Macroreticular Anion Exchange Hybrid Polymers Obtained via Tetrachlorocuprate(II) Ionic Form
}

\author{
Elżbieta Kociołek-Balawejder, Ewa Stanisławska, \\ Irena Jacukowicz-Sobala, and Daniel Ociński \\ Department of Industrial Chemistry, Wrocław University of Economics, Ul. Komandorska 118/120, 53-345 Wrocław, Poland \\ Correspondence should be addressed to Daniel Ociński; daniel.ocinski@ue.wroc.pl
}

Received 27 March 2017; Accepted 5 June 2017; Published 5 July 2017

Academic Editor: Domenico Acierno

Copyright (c) 2017 Elżbieta Kociołek-Balawejder et al. This is an open access article distributed under the Creative Commons Attribution License, which permits unrestricted use, distribution, and reproduction in any medium, provided the original work is properly cited.

\begin{abstract}
Amberlite IRA900 Cl, the macroreticular, polystyrene/divinylbenzene anion exchanger containing quaternary ammonium groups, was used as the support for copper(II) oxide deposition, and, as a result a new hybrid ion exchanger (HIX) was obtained. The CuO deposit was introduced into the anion exchanger structure in two steps conducted batchwise at ambient temperature. First, the functional groups were transformed from the $\mathrm{Cl}^{-}$into the $\mathrm{CuCl}_{4}{ }^{2-}$ form, using $5 \mathrm{~mol} \mathrm{dm}{ }^{-3} \mathrm{NaCl}$ or $\mathrm{HCl}$ solution with $\mathrm{CuCl}_{2}$ being added, and then the intermediate product was contacted with $\mathrm{NaOH} / \mathrm{NaCl}$ solution to precipitate $\mathrm{CuO}$ within the polymer beads. A HIX containing as much as $11.5 \% \mathrm{Cu}$ was obtained. The distribution of the inorganic load within the porous matrix of polymer beads was atypical; $\mathrm{CuO}$ was mainly deposited in the outer parts of the beads and only a small amount was in their inner parts. This may be advantageous in some practical applications concerning the removal of harmful admixtures from waters in sorption processes.
\end{abstract}

\section{Introduction}

Hybrid ion exchangers (HIX) form a major group of hybrid polymers. They are obtained from synthetic ion exchangers into the structure of which an inorganic deposit is introduced. The presence of proper inorganic constituent results in excellent and selective adsorption properties of HIX for removal of target pollutants from contaminated water and wastewater, while same-sign functional groups of polymer matrix greatly enhance the permeation of the pollutant ion and its preconcentration prior to effective sorption by inorganic particles (the Donnan membrane effect) [1-3]. Due to their physical form (spherical beads), HIX can be used, as a bed in a column, in dynamic conditions. Amongst the metal oxides dispersed within the structure of ion exchangers, iron hydr(oxide)s are most commonly studied because of their affinity to many species such as heavy metal cations and harmful oxyanions, availability, and environmental friendliness $[4,5]$. The knowledge relating to HIX keeps growing, covering new products and applications. However, only few reports about synthesis of HIX containing $\mathrm{CuO}$ deposit have been published [6-8].

Copper(II) oxide is a chemical compound with various and unique properties which, due to the development of nanotechnology, finds increasingly wider application $[9,10]$. These include, amongst others, use of $\mathrm{CuO}$ as promising nanostructured adsorbent for removal of undesirable and toxic contaminants such as $\mathrm{As}(\mathrm{III})$ and $\mathrm{As}(\mathrm{V}), \mathrm{Pb}(\mathrm{II})$, and $\mathrm{Cr}(\mathrm{VI})$ ions from water [11-19]. However, the use of $\mathrm{CuO}$ nanoparticles for water purification entails technical problems; particularly separation of the nanostructures from the treated water after the process is difficult. In practical situations, use of such adsorbents needs to be combined with another technique to prevent the release of the nanostructures into the purified water [20]. In order to exploit the good adsorption properties of $\mathrm{CuO}$ and limit the penetration of the cleaned water by the ultrafine particles, it is advisable to immobilize them within porous structure of a polymeric support. Simultaneously, the dispersion of this oxide within the matrix of the supporting polymer prevents agglomeration 
of nanoparticles and ensures a large area of contact between the reagents in the sorption processes.

In our previous study, we have presented the synthesis of a new HIX containing $\mathrm{CuO}$ dispersed within the matrix of a strongly alkaline macroreticular anion exchanger (An) which was used as the polymeric support [8]. Our method of synthesis involved two steps: (a) ion exchange between An in the $\mathrm{OH}^{-}$form and $\mathrm{CuSO}_{4}$ solution aimed at obtaining an anion exchanger doped with $\mathrm{Cu}(\mathrm{OH})_{2}$ particles and (b) the transformation of $\mathrm{Cu}(\mathrm{OH})_{2}$ into $\mathrm{CuO}$ in $\mathrm{NaOH}$ solution at an elevated temperature. The final products contained up to $6.0 \% \mathrm{Cu}$.

In the work of other authors, a HIX containing $\mathrm{CuO}$ was obtained by a column method with the use of a microporous (gel-type) strongly alkaline anion exchanger whose functional groups were converted in the first step into tetrachlorocuprate(II) form [7]. The dispersion process brought the metal coverage of the internal bead surfaces to $4.8 \% \mathrm{Cu}$. Obtained sorbent containing hydrated $\mathrm{CuO}$ within its structure has been studied for phosphate removal from water. However, the ways of synthesis of this material and its characterization were not reported in detail.

The aim of this study was to optimize the $\mathrm{CuO}$ content in the anion exchanger macroreticular structure and to analyze the distribution of the deposit within the beads. They are major factors affecting the HIX's sorption capacity and the sorption and desorption kinetics in water purification processes. Since medium conditions under which the functional groups of the anion exchanger transformed from the $\mathrm{Cl}^{-}$to the $\mathrm{CuCl}_{4}{ }^{2-}$ form have not yet been studied, it is worthwhile to determine the reaction medium composition which ensures quantitative ion exchange reaction. This is a prerequisite for a high $\mathrm{CuO}$ content in the end product obtained after alkalization of the reaction medium. In this study we wanted to answer the following questions: (a) in what conditions does the quantitative transformation of the functional groups of the anion exchanger into the form $\mathrm{CuCl}_{4}{ }^{2-}$ occur? (b) What portion of the copper bonded by the functional groups remains in the ion exchanger phase after the alkalization of the reaction medium? (c) How are the $\mathrm{CuO}$ particles distributed within the polymer beads considering that in the alkaline medium the anionexchangeable functional groups of the anion exchanger repel $\mathrm{Cu}^{2+}$ ions since both reagents have the same charge?

\section{Materials and Methods}

All the chemicals used in this study were of analytical grade. All the solutions were prepared using deionized water. Amberlite IRA900 Cl (Dow Chemical Co.), a macroreticular, polystyrene/divinylbenzene strongly alkaline anion exchange resin containing quaternary ammonium groups (amounting to $3.18 \mathrm{meq} / \mathrm{g}$ of the dry resin), was selected as the macromolecular host material for the $\mathrm{CuO}$ deposit.

The anion exchanger in the $\mathrm{Cl}^{-}$form $\left(\mathrm{An} / \mathrm{Cl}^{-}\right)$was dried at $40^{\circ} \mathrm{C}$ for $24 \mathrm{~h}$. An $\mathrm{An} / \mathrm{Cl}^{-}$sample weighing about $1.0 \mathrm{~g}$ (3.18 meq) was placed in a conical flask and treated with $10 \mathrm{~cm}^{3}$ of $0.5 \mathrm{~mol} \mathrm{dm}{ }^{-3} \mathrm{CuCl}_{2}$ in $\mathrm{HCl}$ solution with a concentration of $2-6 \mathrm{~mol} \mathrm{dm}^{-3}$ and in $\mathrm{NaCl}$ solution with a concentration from $2 \mathrm{~mol} \mathrm{dm}^{-3}$ (pH 2.97) to $5 \mathrm{~mol} \mathrm{dm}^{-3}$ $(\mathrm{pH} 2.50)$. The reagents were shaken at $20^{\circ} \mathrm{C}$ for $1 \mathrm{~h}$. The filtered-off intermediate product was introduced into $1 \mathrm{~mol} \mathrm{dm}^{-3} \mathrm{NaOH}$ in $1 \mathrm{~mol} \mathrm{dm}^{-3} \mathrm{NaCl}$ solution $\left(50 \mathrm{~cm}^{3}\right)$ and was shaken at $20^{\circ} \mathrm{C}$ for $24 \mathrm{~h}$. After the reaction, the sediment was removed through decantation and the filtered-off and washed product was dried at $40^{\circ} \mathrm{C}$ for $24 \mathrm{~h}$.

The $\mathrm{Cu}$ content in the products was determined after dissolving $\mathrm{CuO}$ in acid solution. A sample weighing about $0.5 \mathrm{~g}$ was treated with $10 \mathrm{~cm}^{3}$ of $2 \mathrm{~mol} \mathrm{dm}{ }^{-3} \mathrm{HCl}$ in a conical flask and shaken for $30 \mathrm{~min}$. After this time, the polymer beads were filtered off into a volumetric flask having a volume of $50 \mathrm{~cm}^{3}$. Then $10 \mathrm{~cm}^{3}$ of the solution was drawn; the sample was alkalized with concentrated aqua ammonia and titrated with $0.05 \mathrm{~mol} \mathrm{dm}^{-3}$ EDTA against murexide. Analyses were performed duplicate with standard deviation not exceeding $1.0 \%$.

Microscopic examinations were performed by means of a HITACHI S-3400N scanning electron microscope (SEM) equipped with an energy-dispersive spectrometry (EDS) microanalyzer. Specific surface area and the porous characteristics were determined from the adsorption isotherms for liquid nitrogen at $77 \mathrm{~K}$ using an Accelerated Surface Area and Porosimetry Analyzer (ASAP 2020, 2007, Micromeritics). The crystalline structure was determined using the X-ray diffraction technique (ULTIMA IV/Rigaku).

\section{Results and Discussion}

It is not easy to dope $\mathrm{CuO}$ particles within the matrix of anion exchanger because the precursor of such particles, that is, $\mathrm{Cu}^{2+}$ ions, cannot be ion exchanged onto an anion exchanger. Considering that there exists a copper containing anion, that is, $\mathrm{CuCl}_{4}{ }^{2-}$, we decided to exploit it as the precursor of $\mathrm{CuO}$ with the affinity toward strongly alkaline anion exchanger. Proper concentrations of $\mathrm{HCl}$ and $\mathrm{NaCl}$ solutions, ensuring the quantitative transformation of the anion exchanger functional groups from the $\mathrm{Cl}^{-}$form into the $\mathrm{CuCl}_{4}{ }^{2-}$ form and then proper conditions for transforming the intermediate product in such a way that as much as possible of the $\mathrm{CuO}$ remained in the ion exchanger phase, were sought:

$$
\begin{aligned}
& \mathrm{CuCl}_{2}+2 \mathrm{Cl}^{-} \longrightarrow \mathrm{CuCl}_{4}{ }^{2-} \\
& 2[\mathrm{P}]-\left(\mathrm{N}^{+}\left(\mathrm{CH}_{3}\right)_{3}\right) \mathrm{Cl}^{-}+\mathrm{CuCl}_{4}{ }^{2-} \\
& \longrightarrow\left([\mathrm{P}]-\mathrm{N}^{+}\left(\mathrm{CH}_{3}\right)_{3}\right)_{2} \mathrm{CuCl}_{4}{ }^{2-}+2 \mathrm{Cl}^{-} \\
& \left([\mathrm{P}]-\mathrm{N}^{+}\left(\mathrm{CH}_{3}\right)_{3}\right)_{2} \mathrm{CuCl}_{4}{ }^{2-}+2 \mathrm{OH}^{-}+2 \mathrm{Cl}^{-} \\
& \longrightarrow 2[\mathrm{P}]-\left(\mathrm{N}^{+}\left(\mathrm{CH}_{3}\right)_{3}\right)^{+} \mathrm{Cl}^{-} \# \mathrm{CuO}+4 \mathrm{Cl}^{-}+\mathrm{H}_{2} \mathrm{O}
\end{aligned}
$$

where $[\mathrm{P}]$ is the polymer matrix (macroreticular styrenedivinylbenzene copolymer) and \# stands for deposited within polymer matrix.

Since $\mathrm{CuCl}_{4}{ }^{2-}$ ion forms exclusively in media with a high $\mathrm{Cl}^{-}$ion content, two series of concentrated $\mathrm{NaCl}$ and $\mathrm{HCl}$ solutions were prepared and a precursor, that is, $\mathrm{CuCl}_{2}$, was introduced into them. When the solutions turned green, 


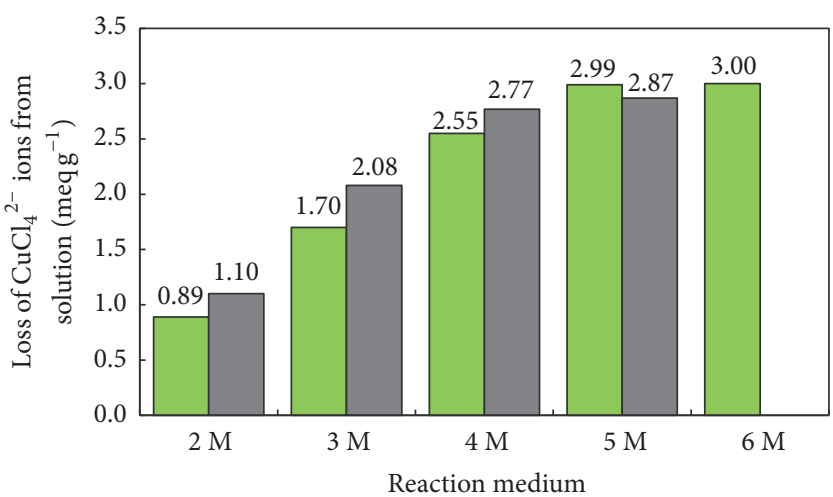

口 $\mathrm{HCl}$

- $\mathrm{NaCl}$

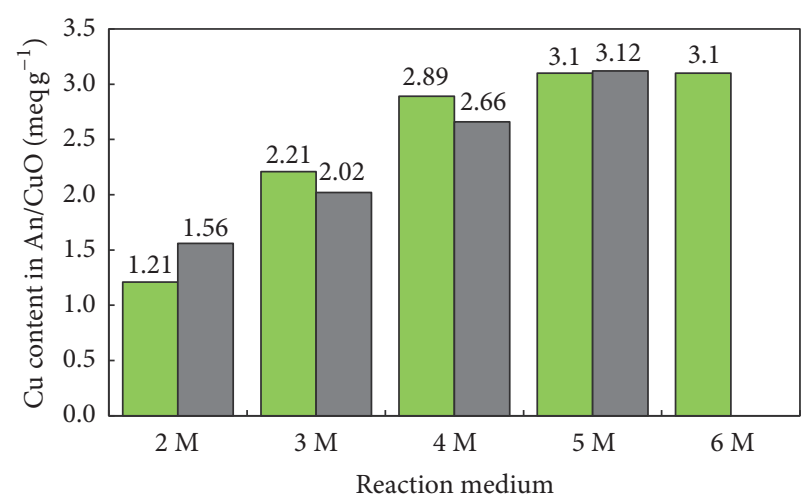

口 $\mathrm{HCl}$

๑ $\mathrm{NaCl}$

(a)

(b)

Figure 1: (a) Loss of $\mathrm{CuCl}_{4}{ }^{2-}$ ions from the solutions in batch reaction at ambient temperature $\left(1.0 \mathrm{~g} \mathrm{An} / \mathrm{Cl}^{-}\right.$in $10 \mathrm{~cm}^{3}$ of $0.5 \mathrm{~mol} \mathrm{dm}{ }^{-3} \mathrm{CuCl}_{2}$ in different media) and (b) $\mathrm{Cu}$ content in corresponded HIX.

this indicated that $\mathrm{CuCl}_{4}{ }^{2-}$ ions had formed. The solutions $\left(10\right.$ meq $\left.\mathrm{CuCl}_{4}{ }^{2-}\right)$ were shaken with anion exchanger samples (3.18 meq). After a few minutes, the cream-coloured anion exchanger beads turned intensively yellow. After $1 \mathrm{~h}$, the beads were separated and the solutions were analyzed for copper content. Figure 1(a) shows that the loss increased with the increase in the concentration of the $\mathrm{NaCl}$ and $\mathrm{HCl}$ solutions (no results for $6 \mathrm{~mol} \mathrm{dm}^{-3} \mathrm{NaCl}$ are shown due to the limited solubility of this salt in water). In the solutions with the highest concentrations, the copper loss reached 3.0 meq and it was close to the anion exchanger's capacity, which indicated that the transformation of the functional groups into the $\mathrm{CuCl}_{4}{ }^{2-}$ form was almost quantitative, consistently with reaction (2). The reaction medium $(\mathrm{HCl}$ or $\mathrm{NaCl})$ was found to have no significant effect on the course of reaction (2). It was found that the reaction was accompanied by a decrease in pH: the initial $\mathrm{pH}$ of $0.5 \mathrm{~mol} \mathrm{dm}^{-3} \mathrm{CuCl}_{2}$ in $5 \mathrm{~mol} \mathrm{dm}^{-3} \mathrm{NaCl}$ was 2.50 and after the reaction it amounted to 2.35 .

The ion exchanger samples were transferred onto filter papers in order to separate as much as possible the reaction medium from them. They could not be washed with deionized water since this would immediately result in the release of copper from the functional groups (the decrease in $\mathrm{Cl}^{-}$concentration causes the decomposition of $\mathrm{CuCl}_{4}{ }^{2-}$ ion). Therefore, the moist samples were introduced into the $\mathrm{NaOH} / \mathrm{NaCl}$ solution $(\mathrm{NaOH}$ caused precipitation of $\mathrm{CuO}$ while $\mathrm{NaCl}$ caused transformation of the ion exchanger functional groups into the $\mathrm{Cl}^{-}$form). In the course of $24 \mathrm{~h}$ long shaking, the ion exchangers changed their colour from yellow to blue (in a few minutes) and then to black (in a few hours). The water phase contained a small amount of black deposit. The HIX samples taken from the $5 \mathrm{~mol} \mathrm{dm}^{-3} \mathrm{HCl}$ and $5 \mathrm{~mol} \mathrm{dm}^{-3} \mathrm{NaCl}$ media contained the largest amount of copper, that is, over $3.1 \mathrm{meq} \mathrm{Cu} \mathrm{g}^{-1}$ (Figure 1(b)). Interestingly, almost all the HIX samples contained markedly more copper than the amount of copper lost from the solutions after the first step. This indicated that some of the $\mathrm{CuO}$ depositing in the ion exchanger came from the decomposition of the free

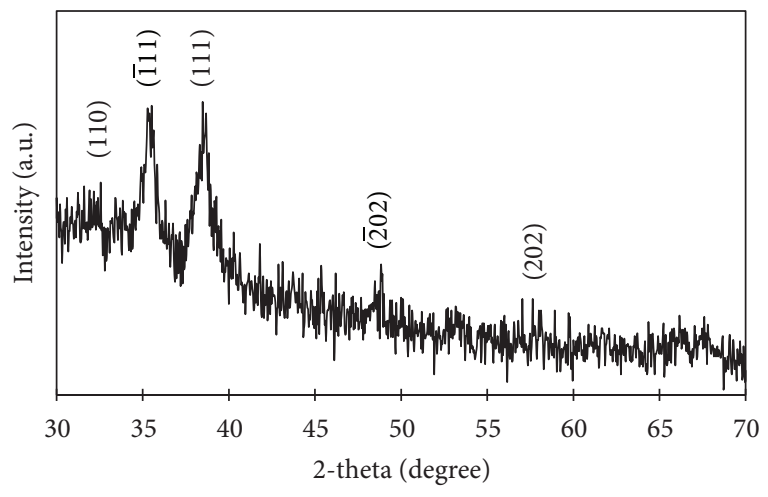

FIGURE 2: X-ray diffraction pattern of the obtained hybrid polymer.

$\mathrm{CuCl}_{4}{ }^{2-}$ ions contained in the water phase remaining in the porous structure of the polymer beads after filtration.

Further research focused on modifying the filtering of the ion exchanger after the first step. Samples taken from the $5 \mathrm{~mol} \mathrm{dm}^{-3} \mathrm{NaCl}$ and $5 \mathrm{~mol} \mathrm{dm}^{-3} \mathrm{HCl}$ media were used for this purpose. Gravitational filtration was replaced with vacuum filtration (a Büchner funnel). The aim of modifying the filtering technique was to more precisely separate the postreaction medium from the ion exchanger. It was found that the vacuum-filtered products subjected to the reaction with $\mathrm{NaOH} / \mathrm{NaCl}$ contained more copper (even to $3.5 \mathrm{meq} \mathrm{Cu} \mathrm{g}^{-1}$ ) than the gravitationally filtered products. This may be due to lower moisture content in the ion exchanger sample after vacuum filtering, whereby the reagent $(\mathrm{NaOH} / \mathrm{NaCl}$ solution) can penetrate faster into the ion exchanger beads.

The chemical composition of the inorganic deposit introduced into supporting, polymeric material was determined by X-ray diffraction (XRD).

The XRD pattern, presented in Figure 2, revealed that the inorganic load in the final product consisted mainly of copper(II) oxide, $\mathrm{CuO}$. The relatively broad reflections at 

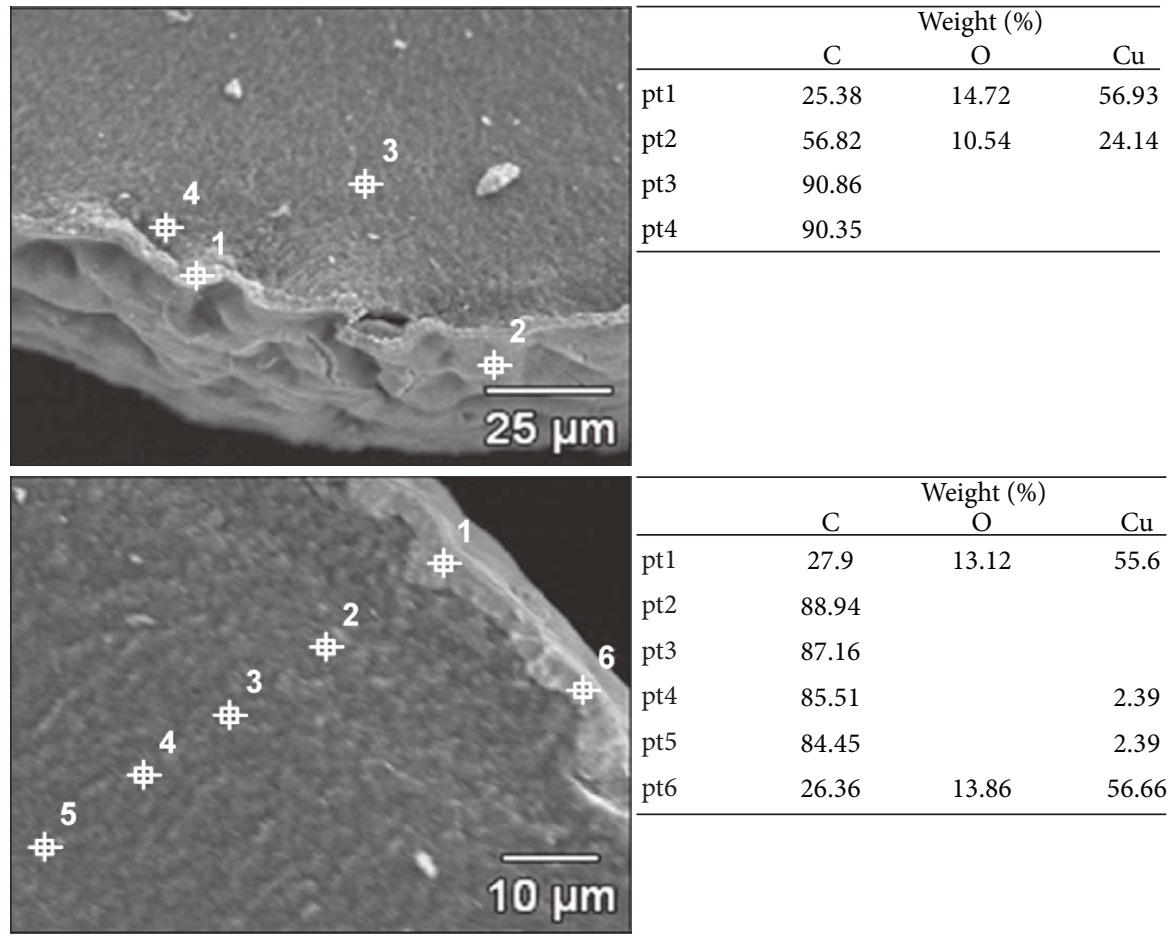

FIGURE 3: SEM image with EDS analysis of the cross section of the polymer bead impregnated with $\mathrm{CuO}$.

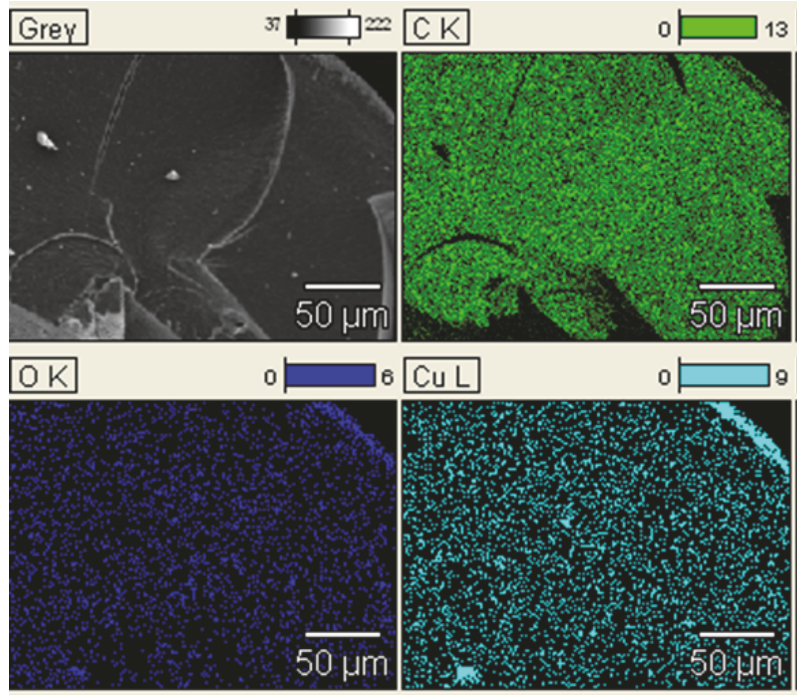

FIGURE 4: SEM image with EDS mapping analysis of distribution of copper, carbon, and oxygen on the cross section of the polymer bead impregnated with $\mathrm{CuO}$.

$2 \theta: 32.5^{\circ}, 35.5^{\circ}, 38.5^{\circ}, 48.5^{\circ}$, and $58.3^{\circ}$ were matched with ICSD card number 87126 . The dispersion of inorganic deposit within the polymer matrix was analyzed using the SEM EDS technique (Figures 3 and 4).

The obtained results show that the precipitated copper(II) oxide was dispersed mainly in the outer parts of the polymeric beads, while their inner parts contained only a very small amount of evenly scattered $\mathrm{CuO}$ (Figures 3 and 4). This may be explained by the course of the copper(II) oxide deposition within the porous structure of the ion exchanger's beads. This process consisted of four main stages: (a) introduction of $\mathrm{CuCl}_{4}{ }^{2-}$ ions into the functional groups, (b) decomposition of tetrachlorocuprate(II) after alkalization, (c) precipitation of $\mathrm{Cu}(\mathrm{OH})_{2}$, and $(\mathrm{d})$ conversion of $\mathrm{Cu}(\mathrm{OH})_{2}$ to $\mathrm{CuO}$. As mentioned earlier, the transformation of the functional groups into the $\mathrm{CuCl}_{4}{ }^{2-}$ form was almost quantitative, ensuring uniform dispersion of $\mathrm{Cu}$ within the polymer beads. As a result of decomposition of tetrachlorocuprate(II), the $\mathrm{Cu}^{2+}$ ions were temporarily formed and diffused from the inner to the outer part of the beads due to electrostatic repulsion. This process was favoured by the presence of macropores within the polymeric structure of the ion exchangers. The contact of highly alkaline bulk solution with the surface of the polymeric bead resulted in immediate precipitation of $\mathrm{Cu}(\mathrm{OH})_{2}$ in the outermost part of the beads. This layer, formed at the first stage of the precipitation process, then acted as a barrier to $\mathrm{Cu}^{2+}$ ions diffused from the bulk phase of the polymer. Precipitated copper(II) hydroxide was then converted into $\mathrm{CuO}$ within a few hours, which resulted in the colour of the beads changing from blue to black. The mechanism of this conversion is reconstructive, involving $\mathrm{Cu}(\mathrm{OH})_{2}$ dissolution followed by $\mathrm{CuO}$ precipitation [21]. The determined specific surface area (Table 1), typical for nonporous materials, confirmed the creation of an almost impermeable layer of copper(II) oxide in the outer part of the polymer beads.

It should also be noted that the presence of the copper in the whole cross section of the beads (Figure 4) and 
TABLE 1: Porous characteristics of the obtained hybrid polymer.

\begin{tabular}{lcc}
\hline$S_{\mathrm{BET}}, \mathrm{m}^{2} \mathrm{~g}^{-1}$ & $\begin{array}{c}V_{T} \text { (pore volumes), } \\
\mathrm{cm}^{3} \mathrm{~g}^{-1}\end{array}$ & $\begin{array}{c}L_{m} \text { (mean pore diameter), } \\
\mathrm{nm}\end{array}$ \\
\hline 2.88 & 0.0069 & 9.54 \\
\hline
\end{tabular}

simultaneously the lack of $\mathrm{CuO}$ microdimensional aggregates (Figure 3) may suggest the formation of nanoparticles. Likewise, the broadening of XRD reflections (Figure 2) indicates that the precipitated particles of $\mathrm{CuO}$ are nanodimensional.

\section{Conclusions}

The obtained hybrid anion exchanger contained considerably more $\mathrm{CuO}$ than the similar products described earlier. The synthesis was conducted in a simple way, that is, batchwise at ambient temperature, without organic solvents. The product contained more deposit compared to that would be expected from the anion exchanger's functional groups content, since $\mathrm{CuO}$ formed not only from the $\mathrm{CuCl}_{4}{ }^{2-}$ ions bound with the ion exchanger but also from the free $\mathrm{CuCl}_{4}{ }^{2-}$ ions derived from the water phase remaining in the polymer beads after vacuum filtration. The specific distribution of copper(II) oxide within the porous polymer structure, "impregnation" of the outer parts of the beads and only a small amount of copper(II) oxide in their inner parts, may be advantageous in some practical applications. In adsorption processes, due to the high content of copper(II) oxide readily available in the outer part of the sorbent beads, a high process kinetic rate may be achieved as well as high regeneration efficiency. However, detailed research needs to be conducted on adsorption properties of the obtained product including equilibrium, kinetics, and column studies.

\section{Conflicts of Interest}

The authors declare that there are no conflicts of interest regarding the publication of this paper.

\section{References}

[1] S. Sarkar, E. Guibal, F. Quignard, and A. K. SenGupta, "Polymersupported metals and metal oxide nanoparticles: synthesis, characterization, and applications," Journal of Nanoparticle Research, vol. 14, no. 2, article 715, 2012.

[2] B. Samiey, C.-H. Cheng, and J. Wu, "Organic-inorganic hybrid polymers as adsorbents for removal of heavy metal ions from solutions: a review," Materials, vol. 7, no. 2, pp. 673-726, 2014.

[3] R. C. Smith, J. Li, S. Padungthon, and A. K. Sengupta, "Nexus between polymer support and metal oxide nanoparticles in hybrid nanosorbent materials (HNMs) for sorption/desorption of target ligands," Frontiers of Environmental Science and Engineering, vol. 9, no. 5, pp. 929-938, 2015.

[4] L. Cumbal and A. K. SenGupta, "Arsenic removal using polymer-supported hydrated iron(III) oxide nanoparticles: role of Donnan membrane effect," Environmental Science \& Technology, vol. 39, no. 17, pp. 6508-6515, 2005.
[5] H. Li, Ch. Shan, Y. Zhang, J. Cai, W. Zhang, and B. Pan, "Arsenate adsorption by hydrous ferric oxide nanoparticles embedded in cross-linked anion exchanger: effect of the host pore structure," ACS Applied Materials \& Interfaces, vol. 5, pp. 3012-3020, 2016.

[6] Z. Feng and T. Sun, "A novel selective hybrid cation exchanger for low-concentration ammonia nitrogen removal from natural water and secondary wastewater," Chemical Engineering Journal, vol. 281, pp. 295-302, 2015.

[7] N. Y. Acelas, B. D. Martin, D. López, and B. Jefferson, "Selective removal of phosphate from wastewater using hydrated metal oxides dispersed within anionic exchange media," Chemosphere, vol. 119, pp. 1353-1360, 2015.

[8] E. Kociołek-Balawejder, E. Stanisławska, and I. JacukowiczSobala, "Synthesis and characterization of CuO-loaded macroreticular anion exchange hybrid polymer," Reactive and Functional Polymers, vol. 100, pp. 107-115, 2016.

[9] Q. Zhang, K. Zhang, D. Xu et al., "CuO nanostructures: synthesis, characterization, growth mechanisms, fundamental properties, and applications," Progress in Materials Science, vol. 60, no. 1, pp. 208-237, 2014.

[10] A. Ananth, S. Dharaneedharan, M.-S. Heo, and Y. S. Mok, "Copper oxide nanomaterials: synthesis, characterization and structure-specific antibacterial performance," Chemical Engineering Journal, vol. 262, pp. 179-188, 2015.

[11] S. Mahdavi, M. Jalali, and A. Afkhami, "Removal of heavy metals from aqueous solutions using $\mathrm{Fe}_{3} \mathrm{O}_{4}, \mathrm{ZnO}$, and $\mathrm{CuO}$ nanoparticles," Journal of Nanoparticle Research, vol. 14, no. 8, article 846, 2012.

[12] W. Xiang, J. Liu, M. Chang, and C. Zheng, "The adsorption mechanism of elemental mercury on $\mathrm{CuO}$ (110) surface," Chemical Engineering Journal, vol. 200-202, pp. 91-96, 2012.

[13] K. J. Reddy, K. J. McDonald, and H. King, "A novel arsenic removal process for water using cupric oxide nanoparticles," Journal of Colloid and Interface Science, vol. 397, pp. 96-102, 2013.

[14] K. J. McDonald, K. J. Reddy, N. Singh, R. P. Singh, and S. Mukherjee, "Removal of arsenic from groundwater in West Bengal, India using $\mathrm{CuO}$ nanoparticle adsorbent," Environmental Earth Sciences, vol. 73, no. 7, pp. 3593-3601, 2015.

[15] K. Z. Elwakeel and E. Guibal, "Arsenic(V) sorption using chitosan $/ \mathrm{Cu}(\mathrm{OH})_{2}$ and chitosan/CuO composite sorbents," Carbohydrate Polymers, vol. 134, pp. 190-204, 2015.

[16] D. K. Singh, S. Mohan, V. Kumar, and S. H. Hasan, "Kinetic, isotherm and thermodynamic studies of adsorption behaviour of $\mathrm{CNT} / \mathrm{CuO}$ nanocomposite for the removal of As(III) and $\mathrm{As}(\mathrm{V})$ from water," RSC Advances, vol. 6, no. 2, pp. 1218-1230, 2016.

[17] A. A. Farghali, M. Bahgat, A. Enaiet Allah, and M. H. Khedr, "Adsorption of $\mathrm{Pb}$ (II) ions from aqueous solutions using copper oxide nanostructures," Beni-Suef University Journal of Basic and Applied Sciences, vol. 2, no. 2, pp. 61-71, 2013.

[18] A. E. Nogueira, A. S. Giroto, A. B. S. Neto, and C. Ribeiro, "CuO synthesized by solvothermal method as a high capacity adsorbent for hexavalent chromium," Colloids and Surfaces A: Physicochemical and Engineering Aspects, vol. 498, pp. 161-167, 2016.

[19] V. K. Gupta, R. Chandra, I. Tyagi, and M. Verma, "Removal of hexavalent chromium ions using $\mathrm{CuO}$ nanoparticles for water purification applications," Journal of Colloid and Interface Science, vol. 478, pp. 54-62, 2016. 
[20] P. Pillewan, S. Mukherjee, T. Roychowdhury, S. Das, A. Bansiwal, and S. Rayalu, "Removal of As(III) and As(V) from water by copper oxide incorporated mesoporous alumina," Journal of Hazardous Materials, vol. 186, no. 1, pp. 367-375, 2011.

[21] D. P. Singh, A. K. Ojha, and O. N. Srivastava, "Synthesis of different $\mathrm{Cu}(\mathrm{OH})_{2}$ and $\mathrm{CuO}$ (nanowires, rectangles, seed-, belt, and sheetlike) nanostructures by simple wet chemical route," Journal of Physical Chemistry C, vol. 113, no. 9, pp. 3409-3418, 2009. 

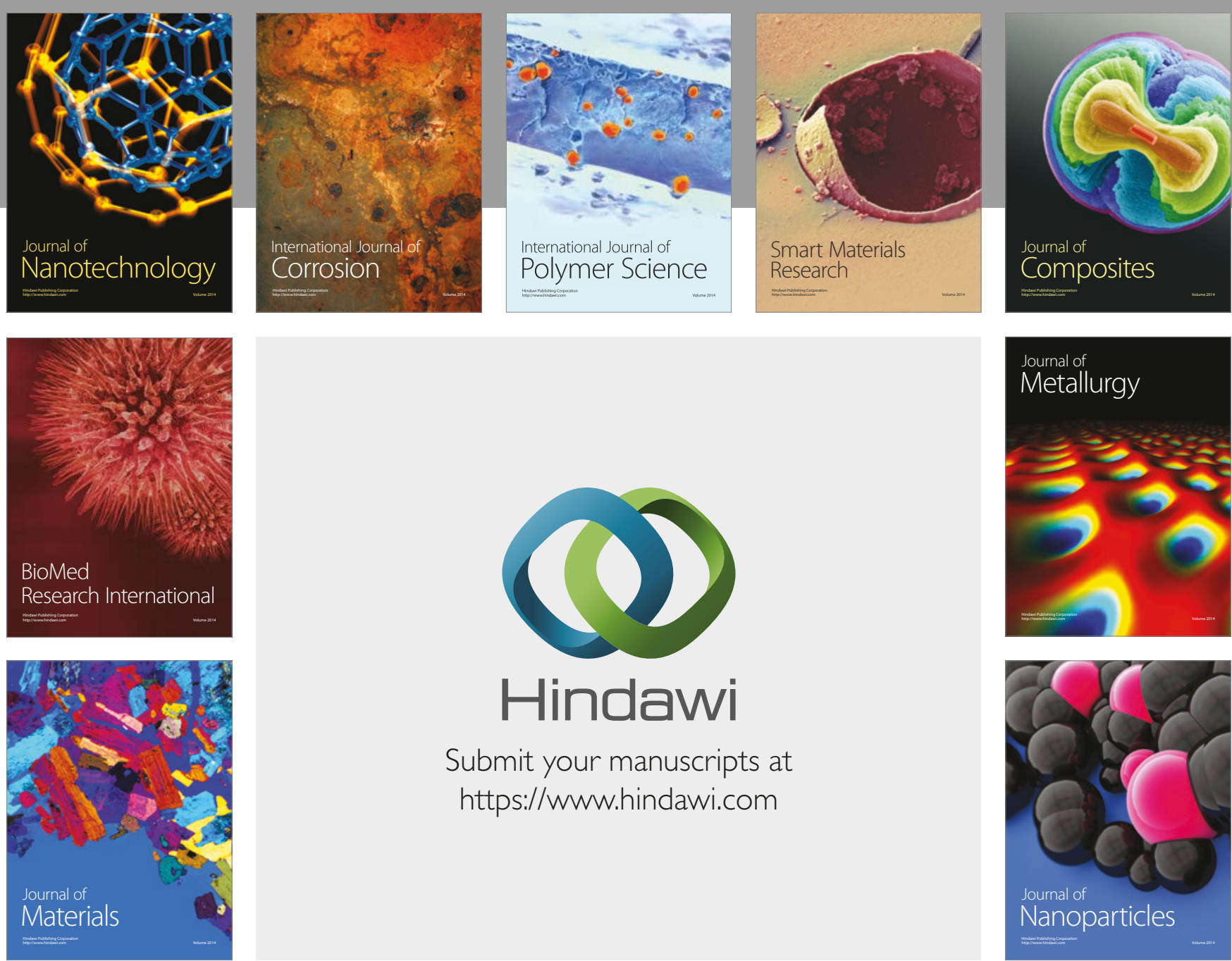

\section{Hindawi}

Submit your manuscripts at

https://www.hindawi.com
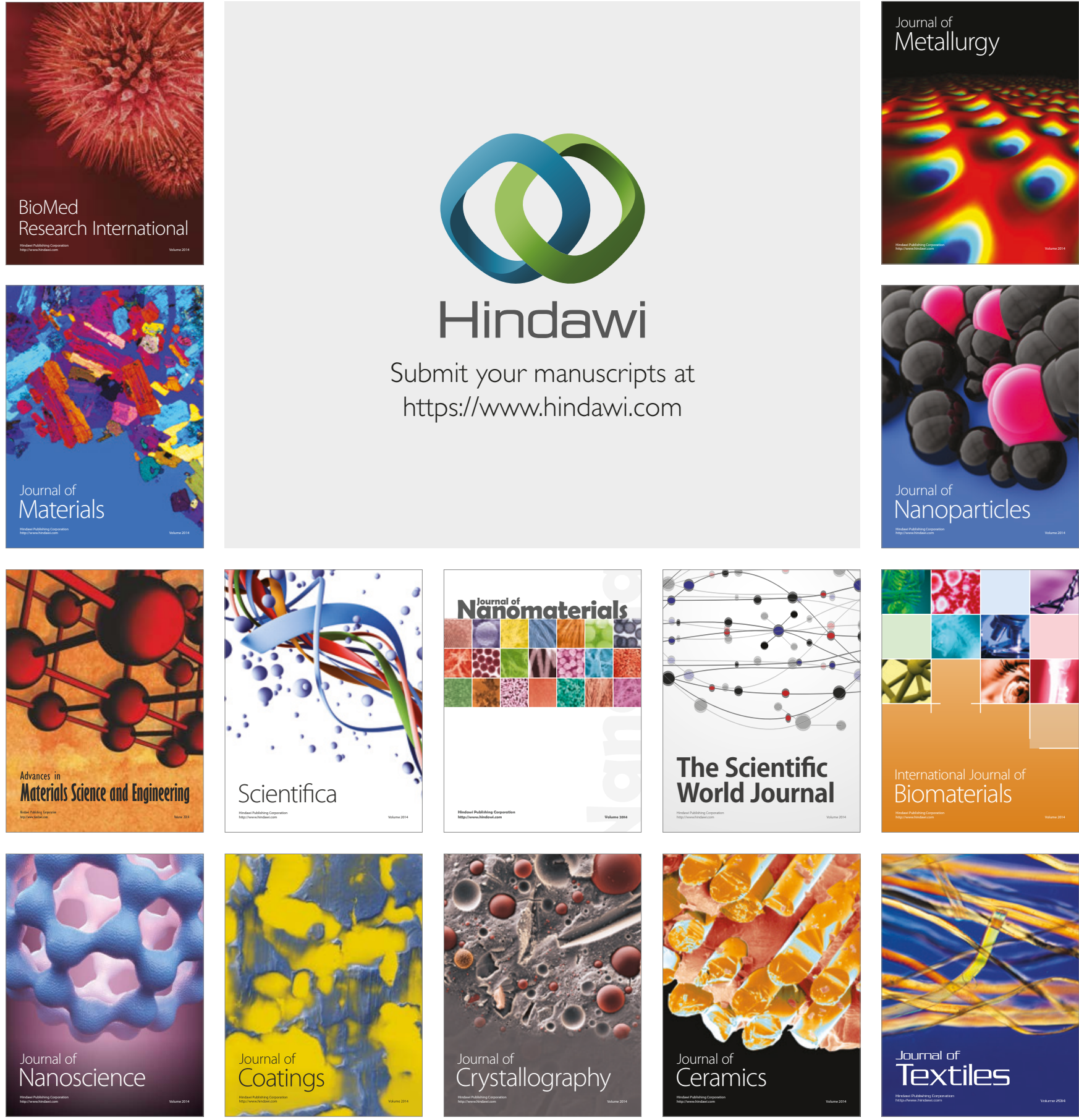

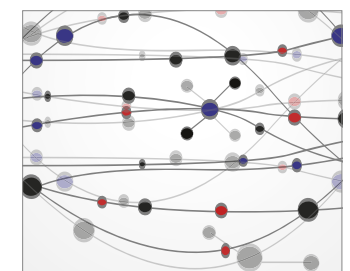

The Scientific World Journal
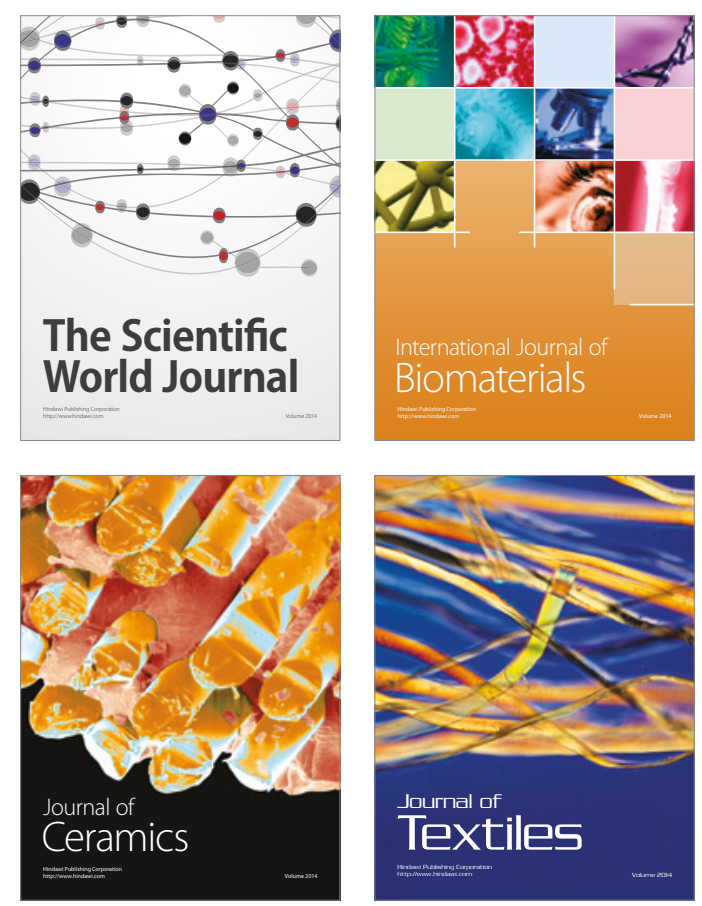